\title{
Functional Measures of Sarcopenia: Prevalence, and Associations with Functional Disability in 10,892 Adults Aged 65 Years and Over from Six Lower- and Middle-Income Countries
}

\author{
Sharon L. Brennan-Olsen ${ }^{1,2}$ (D) Steven J. Bowe ${ }^{3}$ (D) $\cdot$ Paul Kowal $^{4,5,6}$ (D) $\cdot$ Nirmala Naidoo ${ }^{6} \cdot$ Nekehia T. Quashie $^{8}$ (1) $\cdot$ \\ Geeta Eick $^{7}$ (D) . Sutapa Agrawal ${ }^{9}$ (D) $\cdot$ Catherine D’Este ${ }^{10,11^{(D)}}$
}

Received: 28 March 2019 / Accepted: 27 August 2019 / Published online: 10 September 2019

(c) Springer Science+Business Media, LLC, part of Springer Nature 2019

\begin{abstract}
Identification of sarcopenia in lower- and middle-income countries (LMICs) is limited by access to technologies that assess muscle mass. We investigated associations between two functional measures of sarcopenia, grip strength and gait speed (GS), with functional disability in adults from six LMICs. Data were extracted from the World Health Organization (WHO) Study on global AGEing and adult health Wave 1 (2007-2010) for adults ( $\geq 65$ years) from China, Mexico, Ghana, India, Russia and South Africa $(n=10,892,52.8 \%$ women). We calculated country-specific prevalence of low grip strength, slow GS $(\leq 0.8 \mathrm{~m} / \mathrm{s})$, and both measures combined. Using multivariable negative binomial regression, we separately assessed associations between low grip strength, slow GS, and both measures combined, with the WHO Disability Assessment Schedule 2.0, accounting for selected socioeconomic factors. In women, low grip strength ranged from 7 in South Africa to 51\% in India; in men, it ranged from 17 in Russia to $51 \%$ in Mexico. Country-specific proportions of slow GS ranged from 77 in Russia, to 33\% in China. The concomitant presence of both was the lowest in South Africa and the highest in India (12.3\% vs. 33\%). Independent of age, those with both low grip strength and slow GS had between 1.2- and 1.5-fold worse functional disability scores, independent of comorbidities, low education, and low wealth (all country-dependent). Low grip strength, slow GS, and the combination of both, were all associated with higher levels of functional disability, thus indicating these objective measures offer a reasonably robust estimate for potential poor health outcomes.
\end{abstract}

Keywords Grip strength · Gait speed · Function · Strength · Disability · Lower- and middle-income countries · Socioeconomic conditions

Electronic supplementary material The online version of this article (https://doi.org/10.1007/s00223-019-00609-x) contains supplementary material, which is available to authorized users.

Sharon L. Brennan-Olsen

sbrennan@unimelb.edu.au

1 Department of Medicine-Western Health, The University of Melbourne, Level 3, WHCRE Building, C/- Sunshine Hospital, 176 Furlong Road, St Albans, VIC 3021, Australia

2 Australian Institute for Musculoskeletal Science (AIMSS), The University of Melbourne and Western Health, Melbourne, Australia

3 Deakin Biostatistics Unit, Faculty of Health, Deakin University, Geelong, Australia

4 Chiang Mai University Research Institute for Health Sciences, Chiang Mai, Thailand

5 Research Centre for Generational Health and Ageing, University of Newcastle, Newcastle, Australia
6 World Health Organization (WHO) SAGE, Geneva, Switzerland

7 Department of Anthropology, University of Oregon, Eugene, OR, USA

8 College of Population Studies, Chulalongkorn University, Bangkok, Thailand

9 Public Health Foundation of India, New Delhi, India

10 National Centre for Epidemiology and Population Health, Research School of Population Health, Australian National University, Canberra, Australia

11 School of Medicine and Public Health, Faculty of Health and Medicine, The University of Newcastle, Newcastle, Australia 


\section{Introduction}

Sarcopenia is an ageing disorder, characterized by a progressive and generalized skeletal muscle disorder that encompasses an accelerated loss of muscle mass and function [1-3]. Sarcopenia is independently associated with poorer quality of life, physical disability, falls, fractures, and earlier mortality [4-9]. Data, however, suggest that the loss of strength and function may occur much faster than loss of muscle mass [10]. Whilst acknowledging that an international consensus regarding the definition of sarcopenia does not exist, the revised European Working Group on Sarcopenia in Older People (EWGSOP2) definition states that “...sarcopenia is now considered a muscle disease (muscle failure), with low muscle strength overtaking the role of low muscle mass as a principle determinant" [11].

It is well documented that sarcopenia is currently underdiagnosed and undertreated [11]: these data are primarily from higher-income countries, and in contrast, even less is known about populations from lower- and middle-income countries (LMICs). Given that resource-poor LMICs are unlikely to have facilities to assess muscle mass, the EWGSOP2 offers much promise to populations and healthcare professionals in LMICs, as prompt identification of sarcopenia-related functional impairment in clinical settings would be facilitated by undertaking relatively quick, easy and costeffective measures of grip strength and gait speed.

Previous work that has investigated function-based measures of sarcopenia from LMICs had employed 'rapid' rather than 'usual' gait speed, and Asian-specific cut-points had not been applied to determine low grip strength in Asian populations, for instance, from China or India [12]. Other data pertaining to grip strength and/or gait speed have not been investigated according to the cut-points related to sarcopenia diagnosis, but instead present mean data [13, 14]. Furthermore, it is plausible that low grip strength and slow gait speed may be indicative of an earlier onset of functional disability, whilst the combination of the two, which will likely be observed in adults aged $\geq 65$ years, will worsen health outcomes. Whilst the association between sarcopenia and functional capacity is the topic of much research in higher-income countries, relatively little is known about this in populations of LMICs. In this context, we aimed to identify the prevalence of strength and performance-based measures of sarcopenia, and to assess the separate relationships between low grip strength, slow gait speed, and the combination of both, with functional disability in adults aged $\geq 65$ years residing in LMICs.

\section{Methods}

\section{Study Population and Design}

WHO SAGE Wave 1 (2007-2010) is a cross-national study with nationally representative samples of persons aged $\geq 18$ years selected using multistage cluster random sampling from China, Ghana, India, Mexico, the Russian Federation and South Africa [15, 16]. Household-level and person-level population weights, including non-response and post-stratification adjustments, were calculated for each country; briefly, this included sample selection and poststratification correction techniques [15]. For this study, the sample of interest is adults aged $\geq 65$ years $(n=10,892)$. The WHO and the respective implementing agency in each country provided ethical approvals. Written, informed consent was obtained from all participants. Further details on the WHO-SAGE study design and dataset are provided elsewhere [15].

\section{Functional Disability Outcomes}

\section{WHO Disability Assessment Schedule 2.0}

To investigate functional disability, we employed the 12 -item interviewer-administered version of the WHO Disability Assessment Schedule 2.0 (WHODAS 2.0) [17, 18]. WHODAS 2.0 asked participants to estimate the level of difficulty experienced during the previous 30 days in six domains: (i) cognition (understanding and communicating); (ii) mobility (moving and getting around); (iii) self-care (hygiene, dressing, eating and staying alone); (iv) getting along (interacting with other people); (v) life activities (domestic responsibilities, leisure, work and school); and (vi) participation (joining in community activities). Participants responded using a five-point scale $($ none $=1$; mild $=2$; moderate $=3$; severe $=4$; extreme/cannot do=5). The WHODAS 2.0 is directly linked at the level of the six above-mentioned concepts to the International Classification of Functioning, Disability and Health', and as such is a tool applicable to both clinical and general population settings, which enables standardized functional disability levels and profiles to be generated [19]. Summary scores for the WHODAS 2.0 were computed using an algorithm based on 'item-response-theory', which differentially weights the items and the levels of severity. The total WHODAS 2.0 score ranges from 0 to 100 , whereby 0 is no disability and 100 reflects the highest possible level of functional disability $[17,18]$. 


\section{Function-Based Measures of Sarcopenia}

\section{Gait Speed}

The assessment of usual (normal) gait speed involved walking $4 \mathrm{~m}$, on flat ground without any obstacles. Participants were asked to perform the test at their normal walking speed. The test excluded people who were unable to stand but included respondents who used crutches or other assistive devices. Usual (normal) gait speed was measured as a continuous variable and dichotomized for (both sexes) analyses as slow vs normal ( $\leq 0.8$ vs. $>0.8$ $\mathrm{m}$ per second $(\mathrm{m} / \mathrm{s})$, respectively) in accordance with the EWGSOP2 [11]. We excluded times taken to walk the 4-m distance, which were $<1 \mathrm{~s}$ or $>20 \mathrm{~s}$ (range across countries: $0.1-8.6 \%)$.

\section{Grip strength}

Grip strength $(\mathrm{kg})$ was measured twice in both hands using a Smedley Hand Dynamometer (Scandidact Aps, Denmark), whereby the highest mean value of the strongest hand was used as the final measure. Whilst grip strength was assessed as a continuous measure, it was dichotomized for this study using the EWGSOP2 cut-points [11] of $<27 \mathrm{~kg}$ for men and $<16 \mathrm{~kg}$ for women as indicative of low grip strength for all countries, except for China and India where we employed the Asian-specific cutpoints of $<26 \mathrm{~kg}$ for men and $<18 \mathrm{~kg}$ for women [12]. We excluded measures of grip strength that were $\leq 2.5 \mathrm{~kg}$ or $>60 \mathrm{~kg}$ (range across countries: 1.2-6.9\%, except for South Africa which was $15.7 \%$ ).

Participants with the combination of slow gait speed and low grip strength (according to sex- and country-specific cut-points $[11,12]$ were defined.

\section{Body Mass Index}

The weights and heights of participants were ascertained by trained field staff to the nearest $0.1 \mathrm{~kg}$ and $0.1 \mathrm{~cm}$, respectively: these measures were used to calculate body mass index (BMI) $\left(\mathrm{kg} / \mathrm{m}^{2}\right)$. Population-specific BMI categories defined by the WHO as appropriate for adult Europids or adult Asians [20] were applied as follows:

Ghana, Mexico, The Russian Federation, and South Africa: underweight $\left(<18.5 \mathrm{~kg} / \mathrm{m}^{2}\right)$, normal $(18.5-24.9 \mathrm{~kg} /$ $\mathrm{m}^{2}$ ), overweight $\left(25-29.9 \mathrm{~kg} / \mathrm{m}^{2}\right)$, and obese classes I/II/III $\left(\geq 30 \mathrm{~kg} / \mathrm{m}^{2}\right)$.

China, India: underweight $\left(<18.5 \mathrm{~kg} / \mathrm{m}^{2}\right)$, normal $\left(18.5-22.9 \mathrm{~kg} / \mathrm{m}^{2}\right)$, overweight $\left(23-24.9 \mathrm{~kg} / \mathrm{m}^{2}\right)$, and obese classes I/II $\left(\geq 25 \mathrm{~kg} / \mathrm{m}^{2}\right)$.

\section{Parameters of Socioeconomic Conditions}

To determine educational attainment, participants were asked if they had ever been to school; for those that indicated 'yes', they were also asked to identify the highest level of education completed. Educational attainment was mapped to an international standard and categorized as (i) did not complete any formal schooling; (ii) completed some, but not all, primary school; (iii) completed primary school; (iv) completed secondary school or high school (or equivalent); or (v) completed tertiary education, including college, preuniversity, university or post-graduate degree. Due to some small cell counts, educational attainment was collapsed for analyses into two categories: (i) none or completed some or all primary school and (ii) completed all secondary schooling and/or a tertiary degree.

Household wealth was determined from an algorithm based on the presence or absence of a set of household assets and household/structural features and categorized into quintiles, whereby quintile 1 represented the lowest household wealth and quintile 5 represented the highest, as previously applied [21].

\section{Lifestyle Behaviours and Chronic Conditions}

Self-reported data were ascertained regarding smoking status (current smoker, ever smoked in the past, or never smoked) was dichotomized as (i) current and (ii) ever in the past, or never. Alcohol consumption was self-reported as having consumed alcohol (i) during the last 7 days, (ii) ever, or (iii) never, and used in these three categories for analyses. The Global Physical Activity Questionnaire (GPAQ, version 2) [22] was used to measure participation in physical activity and sedentary behaviour [23]. The instrument assesses frequency (days in a typical week) and duration (hours and minutes in a typical day) of moderate and vigorous physical activity in each of the three domains (work, travel and recreation), as well as time spent in sedentary behaviours (sitting or reclining) on a typical day. Studies of concurrent validity have shown highly variable correlations between GPAQ scores (e.g., moderate-to-vigorous physical activity and sedentary behaviour) and both accelerometer and pedometer data, but stronger associations with scores on the International Physical Activity Questionnaire [24, 25]. Test-retest reliability has generally been found to be adequate [24-26]. A binary variable indicating whether or not participants had met WHO physical activity guidelines (150 min/week or more of moderate-to-vigorous physical activity for adults aged $\geq 18$ years [27]) was defined (yes vs. no) [22].

To determine the presence of chronic diseases (arthritis, angina, asthma, diabetes and stroke), symptoms-based algorithms were used. The presence of hypertension was 
determined by systolic blood pressure $(\geq 140)$ or diastolic blood pressure $(\geq 90)$. The total number of chronic conditions and the presence of hypertension were summed for each participant and categorized as (i) none, (ii) one, or (iii) two or more.

\section{Statistical Analyses}

For each country, we describe the sociodemographic characteristics of the sample. Country-specific prevalence of low grip strength, slow gait speed, and the concomitant presence of both measures were calculated with $95 \%$ confidence intervals (95\%). Negative binomial regression models were used to investigate country-specific associations between the individual and combination of function-based measures with the functional disability outcome (WHODAS), adjusting for potential confounders including socioeconomic characteristics, lifestyle behaviours and chronic conditions. We report rate ratios (RR) and 95\% CIs from the regression models. Each country was modelled and reported separately. All analyses were adjusted for the survey design, including the use of sampling weights [15]. Stata 15.0 was used for all analyses, and statistical significance was set at $p<0.05$.

\section{Results}

Country-specific characteristics of the study population ( $n=10,892,52.8 \%$ women) are presented in Table 1. The greatest proportions of participants from all countries were aged 65-74 years (ranging from 60 in Mexico to 75\% in India). For all countries except China, most participants had a gait speed at or slower than $0.8 \mathrm{~m} / \mathrm{s}$ : India $57 \%$, Ghana 70\%, Mexico 59\%, Russia 77\%, and South Africa 63\%. Mean (SD) grip strength varied from $21.6 \mathrm{~kg}$ (8.1) in Mexico to $36.0 \mathrm{~kg}$ (18.7) in South Africa, whilst mean (SD) gait speed was similar between countries, ranging from $0.6(0.3)$ in Russia to 0.9 (0.2) in China (data not shown). In women, the prevalence of low grip strength ranged from 7 in South Africa to $51 \%$ in India, whilst in men it ranged from 17 in Russia to $51 \%$ in Mexico.

Table 2 presents the overall prevalence of low handgrip and slow gait speed combined, which ranged from 12.3 in South Africa to $33.0 \%$ in India; sex-stratified analyses showed the greatest between-sex difference to be $18.8 \%$, observed for South Africa. Prevalence of the concomitant existence of both low handgrip and slow gait speed increased with age, ranging from 9.7 to $49.5 \%$ in China, 29.7 to $60.3 \%$ in India, 19.9 to $44.5 \%$ in Ghana, 11.1 to $60.1 \%$ in Mexico, and $11.9 \%$ to $60.4 \%$ in Russia, except for South Africa where the prevalence was greater in those aged 75-84 years and the lowest in those aged 85 years and older $(15.7 \%$ and $10.4 \%$, respectively).
Independent of increasing age and the number of chronic comorbidities, and after adjustment for potential confounders, those identified as having the concomitant presence (categorical data) of low grip strength and slow gait speed had between 1.2- and 1.5-fold worse functional disability scores compared to those without both factors (Table 3). Countryspecific factors identified as independently associated with greater functional disability scores were low educational attainment (all countries except for South Africa) and low household wealth (China and India), whilst meeting physical activity recommendations showed a protective association for each country, except for Russia.

Results from three negative binomial regression models that present associations between continuous measures of grip strength, gait speed and the combination of both function-based measures with the outcome of functional disability are presented in Supplementary Table 1. The greatest associations with functional disability were seen for gait speed alone, and in models where both gait speed and grip strength (continuous measures) were included. For instance, for every increase in gait speed of $1 \mathrm{~m} / \mathrm{s}$, functional disability score reduced by 0.48 (95\% CI $0.37-0.63$ ) in China, by 0.59 (95\% CI 0.47-0.75) in India and 0.69 (95\% CI 0.55-0.85) in South Africa.

\section{Discussion}

For women in the SAGE Wave 1 study, the prevalence of impaired grip strength was the lowest in South Africa and the highest in India (7\% and 51\%, respectively), whilst for men, the lowest prevalence was $17 \%$ and the highest was 51\% (Russia and Mexico, respectively). The concomitant prevalence of slow gait speed and low grip strength according to (population-specific) cut-points identified by the EWGSOP2 [11] and the Asian Consensus statement for Sarcopenia [12] ranged from 12.3 in South Africa to 33\% in India. The presence of both impaired measures (grip strength and gait speed) in these populations was associated with a higher functional disability level, independent of increasing age, chronic comorbidities, and lower educational attainment and household wealth.

Compared to higher-income countries, very high prevalence of slow gait speed was noted in the SAGE Wave 1 population aged $\geq 65$ years. There exists some gait speed data in population-based adults aged $\geq 65$ years from other LMICs [13, 28]; however, ours are the first gait speed data from Mexico, Ghana, India, Russian Federation and South Africa investigated according to sarcopenia diagnostic criteria. Gait speed data according to sarcopenia cut-points from China showed lower proportions of the study population with slow gait speed than observed in our study [29]: whilst they had applied slightly higher cut-points 
Table 1 Country-specific characteristics of the SAGE Wave 1 study population $(n=10,892)$, presented as $(\%)$, unless otherwise indicated

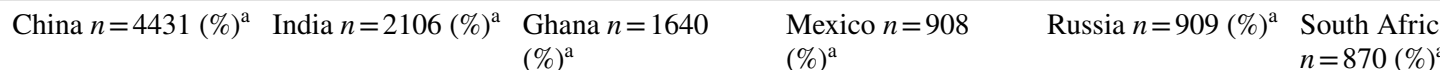

\begin{tabular}{|c|c|c|c|c|c|c|}
\hline \multicolumn{7}{|l|}{ Age group, years } \\
\hline $65-74$ & $2958(67 \%)$ & $1572(75 \%)$ & $1003(61 \%)$ & $546(60 \%)$ & $590(63 \%)$ & $587(67 \%)$ \\
\hline $75-84$ & $1327(30 \%)$ & $449(21 \%)$ & $470(29 \%)$ & $296(33 \%)$ & $314(34 \%)$ & $233(27 \%)$ \\
\hline$\geq 85$ & $146(3 \%)$ & $85(4 \%)$ & $167(10 \%)$ & $66(7 \%)$ & $33(4 \%)$ & $50(6 \%)$ \\
\hline Women & $2257(53 \%)$ & $942(45 \%)$ & $839(51 \%)$ & $537(59 \%)$ & $634(68 \%)$ & $539(62 \%)$ \\
\hline \multicolumn{7}{|c|}{ Gait speed m/s (binary) } \\
\hline$>0.8 \mathrm{~m} / \mathrm{s}$ & $2968(67 \%)$ & $898(43 \%)$ & $498(30 \%)$ & $369(41 \%)$ & $220(23 \%)$ & $322(37 \%)$ \\
\hline$\leq 0.8 \mathrm{~m} / \mathrm{s}$ & $1463(33 \%)$ & $1208(57 \%)$ & $1142(70 \%)$ & $538(59 \%)$ & $717(77 \%)$ & $548(63 \%)$ \\
\hline $\begin{array}{l}\text { Grip strength, kg } \\
\text { [mean (SD)] }\end{array}$ & $25.5(12.3)$ & $22.1(9.3)$ & $25.8(12.1)$ & $21.6(8.1)$ & $27.7(11.2)$ & $36.0(18.7)$ \\
\hline \multicolumn{7}{|l|}{ Women: grip strength ${ }^{\mathrm{b}}$} \\
\hline Normal & $1512(64 \%)$ & $464(49 \%)$ & $651(78 \%)$ & $386(72 \%)$ & $521(82 \%)$ & $500(93 \%)$ \\
\hline Low & $845(36 \%)$ & $478(51 \%)$ & $188(22 \%)$ & $151(28 \%)$ & $113(18 \%)$ & $39(7 \%)$ \\
\hline \multicolumn{7}{|l|}{ Men: grip strength ${ }^{b}$} \\
\hline Normal & $1477(71 \%)$ & $584(50 \%)$ & $531(66 \%)$ & $181(49 \%)$ & $253(83 \%)$ & $246(74 \%)$ \\
\hline Low & $597(29 \%)$ & $580(50 \%)$ & $270(34 \%)$ & $190(51 \%)$ & $50(17 \%)$ & $85(26 \%)$ \\
\hline $\begin{array}{l}\text { WHODAS [mean } \\
\text { (SD)] }\end{array}$ & $13.1(14.6)$ & $33.6(20.1)$ & $29.0(18.5)$ & $19.6(17.5)$ & $26.6(17.7)$ & $21.4(19.5)$ \\
\hline \multicolumn{7}{|l|}{ Educational attainment } \\
\hline $\begin{array}{l}\text { None, or com- } \\
\text { pleted some } \\
\text { primary }\end{array}$ & $3225(73 \%)$ & $1718(82 \%)$ & $1411(86 \%)$ & $789(87 \%)$ & $175(19 \%)$ & $696(80 \%)$ \\
\hline $\begin{array}{l}\text { Completed some/ } \\
\text { all secondary/ } \\
\text { tertiary }\end{array}$ & $1206(27 \%)$ & $388(18 \%)$ & $229(14 \%)$ & $119(13 \%)$ & $762(81 \%)$ & $174(20 \%)$ \\
\hline \multicolumn{7}{|l|}{ Household wealth } \\
\hline Quintile 1 (lowest) & $1214(27 \%)$ & $342(16 \%)$ & $352(21 \%)$ & $215(24 \%)$ & $224(24 \%)$ & $151(17 \%)$ \\
\hline Quintile 2 & $903(20 \%)$ & $406(19 \%)$ & $343(21 \%)$ & $215(24 \%)$ & $206(22 \%)$ & $180(21 \%)$ \\
\hline Quintile 3 & $885(20 \%)$ & $402(19 \%)$ & $346(21 \%)$ & $168(19 \%)$ & $204(22 \%)$ & $171(20 \%)$ \\
\hline Quintile 4 & $788(18 \%)$ & $418(20 \%)$ & $319(19 \%)$ & $165(18 \%)$ & $178(19 \%)$ & $185(21 \%)$ \\
\hline $\begin{array}{l}\text { Quintile 5 (high- } \\
\text { est) }\end{array}$ & $641(14 \%)$ & $538(26 \%)$ & $280(17 \%)$ & $145(16 \%)$ & $125(13 \%)$ & $183(21 \%)$ \\
\hline \multicolumn{7}{|l|}{ Smoker } \\
\hline Never or past & $3413(77 \%)$ & $1089(52 \%)$ & $1415(86 \%)$ & $737(81 \%)$ & $835(89 \%)$ & $671(77 \%)$ \\
\hline Current & $1018(23 \%)$ & $1017(48 \%)$ & $225(14 \%)$ & $171(19 \%)$ & $102(11 \%)$ & $199(23 \%)$ \\
\hline \multicolumn{7}{|c|}{ Alcohol consumption } \\
\hline $\begin{array}{l}\text { Consumed in the } \\
\text { last } 7 \text { days }\end{array}$ & $680(15 \%)$ & $110(5 \%)$ & $443(27 \%)$ & $96(11 \%)$ & $186(20 \%)$ & $103(12 \%)$ \\
\hline $\begin{array}{l}\text { Consumed in the } \\
\text { past }\end{array}$ & $529(12 \%)$ & $184(9 \%)$ & $463(28 \%)$ & $312(34 \%)$ & $456(49 \%)$ & $125(14 \%)$ \\
\hline Never & $3222(73 \%)$ & $1812(86 \%)$ & $734(45 \%)$ & $500(55 \%)$ & $295(31 \%)$ & $642(74 \%)$ \\
\hline \multicolumn{7}{|c|}{ Met physical activity recommendations } \\
\hline No & $1481(33 \%)$ & $623(30 \%)$ & $409(25 \%)$ & $380(42 \%)$ & $191(20 \%)$ & $511(59 \%)$ \\
\hline Yes & $2950(67 \%)$ & $1483(70 \%)$ & $1231(75 \%)$ & $528(58 \%)$ & $746(80 \%)$ & $359(41 \%)$ \\
\hline \multicolumn{7}{|c|}{ Number of chronic conditions } \\
\hline None & $1424(32 \%)$ & $1109(53 \%)$ & $588(36 \%)$ & $254(28 \%)$ & $229(24 \%)$ & $196(23 \%)$ \\
\hline 1 & $2544(57 \%)$ & $795(38 \%)$ & $814(50 \%)$ & $483(53 \%)$ & $437(47 \%)$ & $555(64 \%)$ \\
\hline$\geq 2$ & $463(10 \%)$ & $202(10 \%)$ & $238(15 \%)$ & $171(19 \%)$ & $271(29 \%)$ & $119(14 \%)$ \\
\hline \multicolumn{7}{|c|}{ BMI categories (population-specific) ${ }^{\mathrm{c}}$} \\
\hline $\begin{array}{l}\text { Underweight/ } \\
\text { normal }\end{array}$ & $2106(48 \%)$ & $1680(80 \%)$ & $1280(78 \%)$ & $279(31 \%)$ & $225(24 \%)$ & $270(31 \%)$ \\
\hline
\end{tabular}


Table 1 (continued)

\begin{tabular}{llllll}
\hline & China $n=4431(\%)^{\mathrm{a}}$ & India $n=2106(\%)^{\mathrm{a}}$ & $\begin{array}{l}\text { Ghana } n=1640 \\
(\%)^{\mathrm{a}}\end{array}$ & $\begin{array}{l}\text { Mexico } n=908 \\
(\%)^{\mathrm{a}}\end{array}$ & $\begin{array}{l}\text { Russia } n=909(\%)^{\mathrm{a}} \\
\text { South Africa } \\
n=870(\%)^{\mathrm{a}}\end{array}$ \\
\hline Overweight/obese & $2325(52 \%)$ & $426(20 \%)$ & $360(22 \%)$ & $629(69 \%)$ & $712(76 \%)$ \\
\hline
\end{tabular}

$B M I$ body mass index, SAGE study on global AGEing and adult health, WHODAS World Health Organization Disability Assessment Schedule 2.0

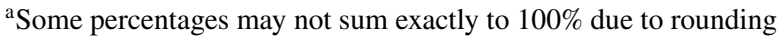

${ }^{\mathrm{b}}$ Grip strength was dichotomized using the EWGSOP2 cut-points [11] of $<27 \mathrm{~kg}$ for men and $<16 \mathrm{~kg}$ for women as indicative of low grip strength for all countries, with the exception of China and India for which we employed the Asian-specific cut-points of $<26 \mathrm{~kg}$ for men and $<18 \mathrm{~kg}$ for women [12]

${ }^{\mathrm{c}} \mathrm{BMI}$ was categorized using the population-specific categories defined by the WHO as appropriate for adult Asians or Europids [20], whereby cut-points for China and India were: underweight $\left(<18.5 \mathrm{~kg} / \mathrm{m}^{2}\right)$, normal $\left(18.5-22.9 \mathrm{~kg} / \mathrm{m}^{2}\right)$, overweight $\left(23-24.9 \mathrm{~kg} / \mathrm{m}^{2}\right)$, and obese classes I/ II $\left(\geq 25 \mathrm{~kg} / \mathrm{m}^{2}\right)$, and for the other countries were underweight $\left(<18.5 \mathrm{~kg} / \mathrm{m}^{2}\right)$, normal $\left(18.5-24.9 \mathrm{~kg} / \mathrm{m}^{2}\right)$, overweight $\left(25-29.9 \mathrm{~kg} / \mathrm{m}^{2}\right)$, and obese classes I/II/III $\left(\geq 30 \mathrm{~kg} / \mathrm{m}^{2}\right)$. Due to small cell sizes, the BMI categories of underweight and normal were combined, as were the categories of overweight and obese

of $<0.98 \mathrm{~m} / \mathrm{s}$ for males and $<0.88 \mathrm{~m} / \mathrm{s}$ for females, this discrepancy is unlikely to have influenced such a difference in findings between studies. Rather, the younger age of their study population, is likely to have biased their results.

Similarly, little is known about the prevalence of muscle strength in LMICs according to diagnostic cut-points for sarcopenia [30], except for China, in which, as observed for gait speed, the proportion of those with low grip strength was lower than we observed in our current study: differences that are likely due to the younger age group of their population [29]. Published data from the WHO SAGE (Wave 1) in younger adults from South Africa aged $\geq 50$ years shows greater mean grip strength [14] than we observed in our study which was contained to those aged $\geq 65$ years. In addition, normative data for grip strength exist for Indian populations aged $\geq 50$ years, which shows slightly greater strength than we observed in our older population [28]. The presence of low grip strength in up to two-thirds of our study population suggests a concerning trajectory towards frailty in countries where early assessment, diagnosis and treatment for sarcopenia are less likely than may be expected in higher-income countries.

The revised EWGSOP2 consensus regarding sarcopenia identified that, in clinical practice, low grip strength is enough to trigger assessment of causes and start intervention for sarcopenia [11], which is indicative of an increasing focus on muscle strength rather than muscle mass as a key determinant of sarcopenia $[4,11,31,32]$. This change offers much promise to populations and healthcare professionals in LMICs, as prompt identification of sarcopenia-related functional impairment in clinical settings would be facilitated by ascertaining these quick, easy and cost-effective measures. Similarly, ascertaining measures of gait speed to evaluate physical performance are quick, easy and cost-effective [33]. The SAGE Wave 1 cohort encompasses measures of grip strength and gait speed that were collected in the field by trained research staff; this suggests the feasibility of a clinical assessment pathway in LMICs.

Low education was an independent risk factor for the association between the concomitant presence of low grip strength and slow gait speed and a greater functional disability score for China, India, Russia, South Africa, whilst low household wealth was independently associated with worse functional disability outcomes for the SAGE population from China, India and Ghana. Whilst data from other populations are scarce, the association of low education with poorer grip strength was observed by Castell et al. in a study of Spanish adults [34]. It is notable that, except for Russia, a high proportion of SAGE Wave 1 participants were identified as having low educational attainment (ranging from 73 to $87 \%$ ). However, some conflicting results are seen in a multi-cohort study involving 37 cohorts from 24 countries ( $n=109,107$ adults, age range 45-90 years) [13], in which men of low socioeconomic status (SES), but not women, were observed to have the same gait speed as those of higher SES. That study reported that, compared to their same-sex counterparts of higher SES, men of lower SES lost 6.6 years of functioning, and women lost 4.6 years [13]. Given the representativeness of the complete SAGE population (aged $\geq 50$ years), we may speculate that populations of LMICs may have a disproportionately greater risk of functional disability compared to higher-income countries.

In relatively resource-poor countries where healthcare resources are scarce, or access is limited, maintaining functional capacity is imperative to survival. Lower household wealth and lower educational attainment may predispose populations to manual labour, this, combined with lower functional capacity, would increase the difficulty of performing job requirements with ease, and without pain or injury. Current global non-communicable disease initiatives do not list musculoskeletal diseases within the 'top four' priorities [35]. Thus, the burden of functional impairment, chronic disability, and possibly frailty, will be compounded by the 
social stressors which require individuals to work and fulfil community roles regardless of functional status. It is notable, as with many other chronic health conditions in populations of LMICs, that the treatment gap, and indeed the diagnosis gap, for sarcopenia and/or functional impairments is at odds with the WHO Constitution that recognises "...the highest attainable standard of health [is] a fundamental right of every human being" [36].

Our study has some strengths. First, our findings refine the previous evidence-base by (i) applying EWGSOP2 recommendations [11] of Asian-specific cut-points of grip strength [12] to the SAGE populations from China and India; however, we acknowledge that grip strength adjusted for BMI was previously supported by the initial consensus statement of the EWGSOP [37]. Our findings also refine the previous evidence-base by investigating 'usual' gait speed, which is in line with all international guidelines for sarcopenia assessment, rather than 'rapid' gait speed, as has often been reported from LMICs. Although assessing usual gait speed for sarcopenia diagnosis in clinical settings involves using a 6-m course and measuring the time taken to walk the middle $4 \mathrm{~m}$, allowing $1 \mathrm{~m}$ on either side for acceleration and deceleration; nonetheless, these two improvements on previous analyses of the SAGE data align with the current literature and evidence in the sarcopenia field. Furthermore, this is the first study to link prevalence data of grip strength and gait speed with functional disability outcomes in populations from LMICs. Our study also has some limitations. Overall, SAGE data are representative of the national populations aged $\geq 50$ years; however, we are unable to comment on the generalizabiility of our findings, given that our current study was limited to SAGE participants aged $\geq 65$ years. The SAGE data do not include institutionalized adults or other populations without a fixed address. We cannot exclude the possibility of administrative errors in data entry in different countries, and thus, we excluded measures of grip strength that were $\leq 2.5 \mathrm{~kg}$ or $>60 \mathrm{~kg}$ and measures of gait speed $<1 \mathrm{~m} / \mathrm{s}$ and $>20 \mathrm{~m} / \mathrm{s}$ (none of which were related to the use of assistive devices): given this, our results are likely an underestimation of the concomitant presence of low grip strength and slow gait speed and the associated impact on functional disability. Although protein consumption is a key risk factor for sarcopenia, along with overall poorer quality nutritional intake, we were unable to investigate the role played by this, given the questions about protein intake were not asked in the SAGE Wave 1 interviews. In addition, we acknowledge that energy intake in LMICs may be a key contributor to poor body composition. Finally, we are unable to comment on whether there are cultural differences in gait speed.

Individually, and combined, low grip strength and slow gait speed were associated with worse functional disability. These data hint at several determinants commonly 


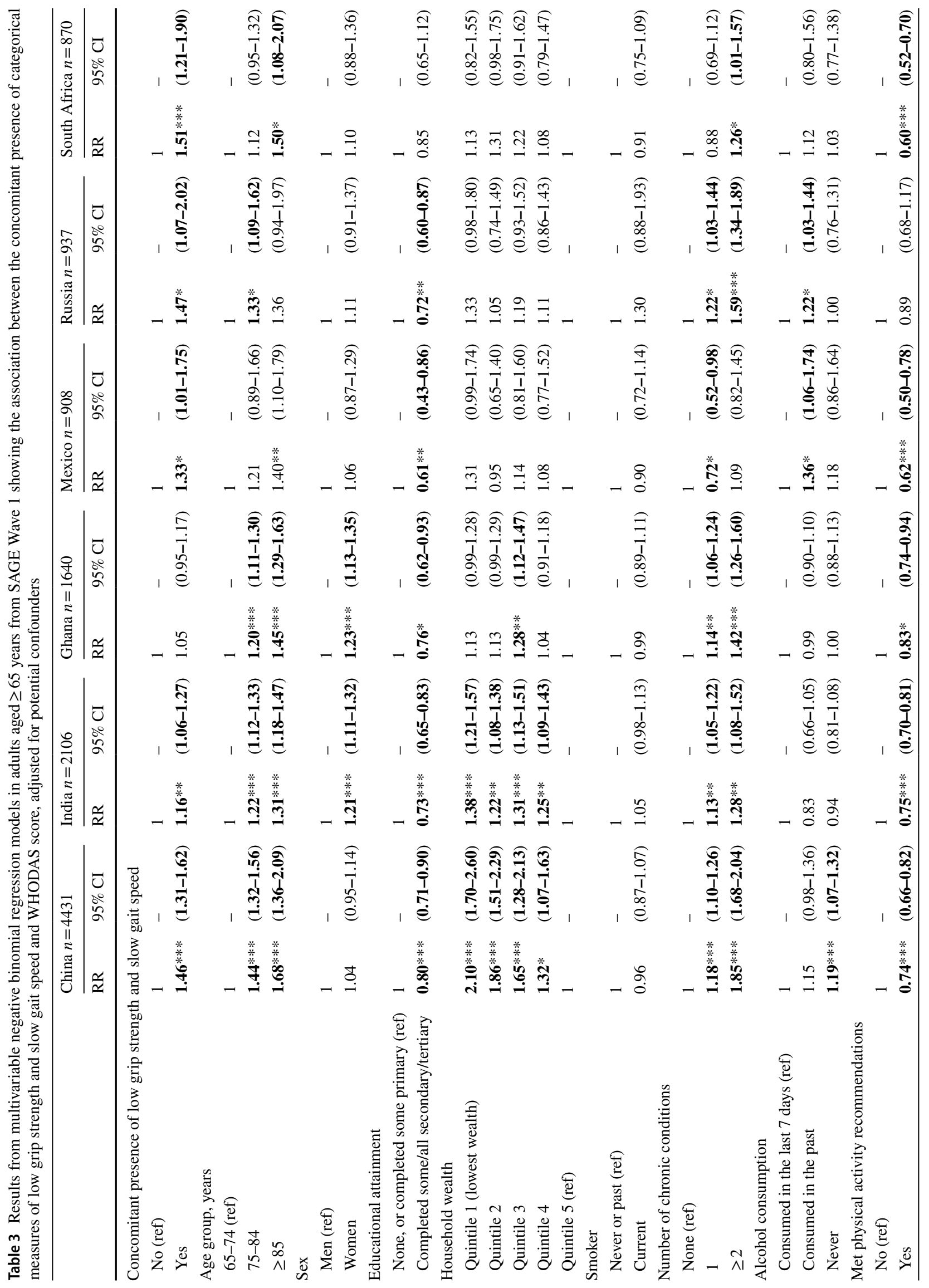


contributing to frailty in LMICs where early assessment, diagnosis and treatment for functional impairments are less likely, compared to higher-income countries. Our current findings have implications for national efforts to achieve universal health coverage and to prioritise healthcare resources towards preventing trajectories towards functional disability and frailty: the measurements of gait speed and grip strength are simple to perform in LMICs' settings.

Acknowledgements SLB-O is the recipient of a Career Development Fellowship from the National Health and Medical Research Council (NHMRC) of Australia (1107510). SAGE is supported by WHO and the Division of Behavioral and Social Research (BSR) at the US National Institute on Aging (NIA) through interagency agreements (OGHA 04034785; YA1323-08-CN-0020; Y1-AG-1005-01) with WHO. In addition, the governments of Shanghai, China and South Africa provided financial or other support for Wave 1 of their national SAGE study. All collaborating institutions provided substantial resources to conduct their respective studies. We thank the participants in each country for their contributions to SAGE and acknowledge the contributions and expertise of the country-specific investigators and their respective survey teams. We acknowledge the intellectual input of Dr Jesse Zanker and Mr Steven Phu regarding recommended measurement of, and cut-points for, gait speed and grip strength in terms of sarcopenia assessment.

\section{Compliance with Ethical Standards}

Conflict of interest Sharon L. Brennan-Olsen, Steven J. Bowe, Paul Kowal, Nirmala Naidoo, Nekehia T. Quashie, Geeta Eick, Sutapa Agrawal, and Catherine D'Este declare no conflict of interest.

Human and Animal Rights and Informed Consent This article contains studies with human subjects and all participants gave written informed consent in accordance with the Declaration of Helsinki. This study did not include animals.

\section{References}

1. Scott D, de Courten B, Ebeling PR (2016) Sarcopenia: a potential cause and consequence of type 2 diabetes in Australia's ageing population? Med J Aust 205:329-333

2. Narici MV, Mafulli N (2010) Sarcopenia: characteristics, mechanisms and functional significance. Br Med Bull 95:139-159

3. Miljkovic N, Lim J-Y, Miljkovic I, Frontera WR (2015) Aging of skeletal muscle fibers. Ann Rehabil Med 39:155-162

4. Schaap LA, van Schoor NM, Lips P, Visser M (2018) Associations of sarcopenia definitions, and their components, with the incidence of recurrent falling and fractures: the Longitudinal Aging Study Amsterdan. J Gerontol 73:1199-1204

5. Mijnarends DM, Schols JMGA, Halfens RJG, Meijers JMM, Luiking YC, Verlaan S, Evers SMAA (2016) Burden-of-illness of Dutch community-dwelling older adults with sarcopenia: health related outcomes and costs. Eur Geriatr Med 7:276-284

6. Reijnierse EM, Trappenburg MC, Leter MH, Blauw GJ, Sipila S, Sillanpaa E, Narici MV, Hogrel JY, Butler-Browne G, McPhee JS, Gapeyeva H, Paasuke M, de van der Schueren MA, Meskers CG, Maier AB (2015) The impact of different diagnostic criteria on the prevalence of sarcopenia in healthy elderly participants and geriatric outpatients. Gerontology 61:491-496 
7. Volpato S, Bianchi L, Cherubini A, Landi F, Maggio M, Savino E, Bandinelli S, Ceda GP, Guralnik JM, Zuliani G, Ferrucci L (2014) Prevalence and clinical correlates of sarcopenia in communitydwelling older people: application of the EWGSOP definition and diagnostic algorithm. J Gerontol Ser A 69:438-446

8. Beaudart C, Rizzoli R, Bruyere O, Reginster J-Y, Biver E (2014) Sarcopenia: burden and challenges for public health. Arch Public Health 72:45

9. Landi F, Liperoti R, Russo A et al (2012) Sarcopenia as a risk factor for falls in elderly individuals: results from the ilSIRENTE study. Clin Nutr 31:652-658

10. Clark BC, Manini TM (2008) Sarcopenia dynapenia. J Gerontol Ser A 63:829-834

11. Cruz-Jentoft AJ, Bahat G, Bauer J, Boirie Y, Bruyere O, Cederholm T, Cooper C, Landi F, Rolland Y, Sayer AA, Schneider SM, Sieber CC, Topinkova E, Vandewoude M, Visser M, Zamboni M, Writing Group for the European Working Group on Sarcopenia in Older People 2 (EWGSOP2), and the Extended Group for EWGSOP2 (2019) Sarcopenia: revised European consensus on definition and diagnosis. Age Ageing 48:16-31

12. Chen LK, Liu LK, Woo J, Assantachai P, Auyeung TW, Bahyah KS, Chou MY, Chen LY, Hsu PS, Krairit O, Lee JS, Lee Y, Liang CK, Limpawattana P, Lin CS, Peng LN, Satake S, Suzuki T, Won CH, Wu SN, Zhang T, Zeng P, Akishita M, Aria H (2014) Sarcopenia in Asia: consensus report of the Asian Working Group for sarcopenia. J Am Med Dir Assoc 15:95-101

13. Stringhini S, Carmeli C, Jokela M, Avendano M, McCrory C, d'Errico A, Bochud M, Barros H, Cost G, Chadeau-Hyam M, Delpierre C, Gandini M, Fraga S, Goldberg M, Giles GG, Lassale C, Kenny RA, Kelly-Irving M, Paccaud F, Layte R, Muennig P, Marmot MG, Ribeiro AI, Severi G, Steptoe A, Shipley MJ, Zins M, Mackenbach JP, Vineis P, Kivimaki M, for the LIFEPATH Consortium (2018) Socioeconomic status, non-communicable disease risk factors, and walking speed in older adults: multi-cohort population based study. BMJ 360:k1046

14. Ramlagan S, Peltzer K, Phaswana-Mafuya N (2014) Hand grip strength and associated factors in non-institutionalised men and women 50 years and older in South Africa. BMC Res Notes 7:8

15. Kowal P, Chatterji S, Naidoo N, Biritwum R, Fan W, Ridaura RL, Maximova T, Arokiasamy P, Phaswana-Mafuya N, Williams S, Snodgrass JJ, Minicuci N, E'Este C, Peltzer K, Boerma JT, the SAGE collaborators (2012) Data resource profile: the World Health Organization Study on global AGEing and adult health (SAGE). Int J Epidemiol 41:1639-1649

16. Chatterji S (2013) World Health Organization's (WHO) Study global AGEing and adult health (SAGE). BMC Proc 7:S1

17. World Health Organization (2010) World Health Organization Disability Assessment Schedule II (WHO-DAS II). WHO. http:// www.who.int/classifications/icf.en/ Accessed Aug 2018

18. World Health Organization (2010) Measuring health and disability: manual for WHO disability assessment schedule (WHODAS 2.0). In: Ustun TB, Kostanjsek N, Chatterji S, Rehm J (ed). WHO, Geneva

19. World Health Organization (2018) WHO Disability Assessment Schedule 2.0 (WHODAS 2.0). https://www.who.int/classifications /icf/more_whodas/en/) Accessed Feb 2019

20. World Health Organization (2000) The Asia-Pacific perspective: redefining obesity and its treatment. WHO Western Pacific Region, Geneva

21. Brennan-Olsen SLSS, Viikari-Juntura E, Ackerman IN, Bowe SJ, Kowal P, Naidoo N, Chatterji S, Wluka AE, Leech MT, Page RS, Sanders KM, Gomez F, Duque G, Green D, Mohebbi M (2018) Arthritis diagnosis and symptoms are positively associated with specific physical job exposures in lower- and middle-income countries: cross-sectional results from the World Health Organization's Study on global AGEing and adult helath (SAGE). BMC Public Health 8:1
22. Cleland CLHR, Kee F, Cupples ME, Sallis JF, Tully MA (2014) Validity of the Global Physical Activity Questionnaire (GPAQ) in assessing levels and change in moderate-vigorous physical activity and sedentary behaviour. BMC Public Health 14:1255

23. Gaskin CJ, Orellana L (2018) Factors associated with physical activity and sedentary behaviour in older adults from six low- and middle-income countries. Int J Environ Res Public Health 15:908

24. Bull FC, Maslin TS, Armstrong T (2009) Global Physical Activity Questionnaire (GPAQ): nine country reliability and validity study. J Phys Act Health 6:790-804

25. Herrmann SD, Heumann KJ, Der Ananian CA, Ainsworth BE (2013) Validity and reliability of the Global Physical Activity Questionnaire (GPAQ). Meas Phys Educ Exerc Sci 17:221-235

26. Chu AHY, Ng SHX, Koh D, Muller-Riemenschneider F (2015) Reliability and validity of the self- and interviewer-administered versions of the Global Physical Activity Questionnaire (GPAQ). PLoS ONE 10:e0136944

27. World Health Organization (2010) Global recommendations on physical activity for health. WHO, Geneva

28. Gunasekaran V, Banerjee J, Dwivedi SN, Upadhyay AD, Chatterjee P, Dey AB (2016) Normal gait speed, grip strength and thirty seconds chair stand test among older Indians. Arch Gerontol Geriatr 67:171-178

29. Zeng P, Wu S, Han Y, Liu J, Zhang Y, Zhang E, Zhang Y, Gong H, Pang J, Tang Z, Liu H, Zheng X, Zhang T (2015) Differences in body composition and physical functions associated with sarcopenia in Chinese elderly: reference values and prevalence. Arch Gerontol Geriatr 60:118-123

30. Bohannon RW (2015) Muscle strength: clinical and prognostic value of hand-grip dynamometry. Curr Opin Clin Nutr Metab Care 18:465-470

31. Alley DE, Shardell MD, Peters KW, McLean RR, Dam T-TL, Kenny AM, Fragala MS, Harris TB, Kiel DP, Guralnik JM, Ferrucci L, Kritchevsky SB, Studenski SA, Vassileva MT, Cawthon PM (2014) Grip strength cutpoints for the identification of clinically relevant weakness. J Gerontol Ser A 69:559-566

32. Ibrahim K, May C, Patel HP, Baxter M, Sayer AA, Roberts H (2016) A feasibility study of implementing grip strength measurement into routine hospital practice (GRImP): study protocol. Pilot Feasibility Study 2:27

33. Cesari M, Kritchevsky SB, Newman AB, Simonsick EM, Harris TB, Penninx BW, Brach JS, Tylavsky FA, Satterfield S, Bauer DC, Rubin SM, Visser M, Pahor M, for the Health ABC Study (2009) Added value of physical performance measures in predicting adverse health-related events: results from the Health, Aging, and Body Composition Study. J Am Geriatr Soc 57:251-259

34. Castell M-V, Sanchez M, Julian R, Queipo R, Martin S, Otero A (2013) Frailty prevalence and slow walking speed in persons age 65 and older: implications for primary care. BMC Family Pract $14: 86$

35. Hoy D, Geere JA, Davatchi F, Meggitt B, Barrero LH (2014) A time for action: opportunities for preventing the growing burden and disability from musucloskeletal conditions in low- and middle-income countries. Best Pract Res Clin Rheumatol 28:377-393

36. World Health Organization (2015) Health and human rights. In: WHO (ed) Geneva

37. Fried LP, Tangen CM, Walston J, Newman AB, Hirsch C, Gottdiener J, Seeman T, Tracy R, Kop WJ, Burke G, McBurnie MA (2001) Frailty in older adults: evidence for a phenotype. J Gerontol 56:M146-M157

Publisher's Note Springer Nature remains neutral with regard to jurisdictional claims in published maps and institutional affiliations. 